\title{
Perioperative Transesophageal Echocardiography in Myectomy Procedure -4 Cases Report
}

\author{
Marcello Fonseca Salgado-Filho, ${ }^{1,2 *}$, Adrielle Aprígio de Queiroz ${ }^{2}$, Cássia Franco Matheus ${ }^{2}$, Julianne Moreira \\ Belo Crolman², Rafael Teixeira dos Santos ${ }^{2}$ and Maia Nogueira Crown Guimarães ${ }^{3}$
}

${ }^{1}$ Intraoperative Transesophageal Echocardiography coordinator, Brazilian Society of Anesthesiology, Brazil

${ }^{2}$ Santa Casa de Misericórdia de Juiz de Fora, Brazil

${ }^{3}$ Hospital Sírio Libanês, Brazil

Submission: August 08, 2017; Published: August 29, 2017

*Corresponding author: Marcello Fonseca Salgado Filho, Intraoperative TransesophagealEchocardiography Coordenator, Brazilian Society of Anesthesiology, Brazil, Email: mfonsecasalgado@hotmail.com

\begin{abstract}
Background: Asymmetric septal hypertrophy is the most prevalent form of hypertrophic cardiomyopathy. The aim of this series of cases is to demonstrate the measures performed by perioperative transesophageal echocardiography (TEE) during myectomy procedures.

Methods: A retrospective analysis of the echocardiography exams from patients who underwent myectomy procedure from January 2015 to January 2017 was developed. Were excluded patients who underwent emergency surgeries, combined surgery and patients who had already septal coronary artery alcoholization.

Results: A total of 4 patients were evaluated in the period from 2015 to 2017. They were all women, ASA 3 with a mean age of $61 \pm 8,7$ years old. The left ventricle outflow tract (LVOT) peak gradient pre-CPB was 114,4 $\pm 50,6 \mathrm{mmHg}$ and post-CPB was 42,4 46,3mmHg. The LVOT mean gradient pre-CPB was $52,4 \pm 19,9 \mathrm{mmHg}$ and post-CPB was $21,4 \pm 25,6 \mathrm{mmHg}$. The mitral coaptation-septal distance (C-sept) pre-CPB was $1,4 \pm 0.4 \mathrm{~cm}$ and post-CPB was $2,2 \pm 0,2 \mathrm{~cm}$. The vena contracta pre-CPB was $0,5 \pm 0,2 \mathrm{~cm}$ and post-CPB was $0,4 \pm 0,3 \mathrm{~cm}$. The ejection fraction pre- $\mathrm{CPB}$ was $66,5 \pm 1,3 \%$ and post-CPB was $53 \pm 2,7 \%$. The CBP clamp time was $50,3 \pm 30,7 \mathrm{~min}$ and the CPB time $82 \pm 42,6 \mathrm{~min}$. One patient died in the ICU due a low output syndrome after CPB.
\end{abstract}

Conclusion: The perioperative TEE assisted in the decision making regarding the anatomical structures to be resected, evaluated the severity of mitral regurgitation before and after resection and guided the surgical team regarding the LVOT peak gradient and C-sept distance.

\section{Background}

Asymmetric septal hypertrophy (ASH) is the most prevalent form of hypertrophic cardiomyopathy [1]. In ASH, the systolic anterior movement (SAM) of the mitral valve develop a dynamic obstruction in the left ventricular outflow tract (LVOT) that can cause low cardiac output and pulmonary edema [2]. Among the forms of treatment, myectomy surgery stands out [1-3]. Patients with labile obstruction, peak LVOT pressure gradients $\geq 50 \mathrm{~mm} \mathrm{Hg}$ during exercise, resting gradients $>30 \mathrm{~mm} \mathrm{Hg}$ and patients with NYHA class II through IV symptoms refractory to medical therapy are the ones that will benefit from the surgical procedure [1]. The aim of this series of cases is to demonstrate the measures performed by perioperative transesophageal echocardiography during myectomy procedures.

\section{Methods}

After approval by the Ethics Committee of Santa Casa de Misericórdia of Juiz de Fora, retrospective analysis were developed in the echocardiography exams from patients underwent myectomy procedure from January 2015 to January 2017. Were included in these study patients between 18 to 70 years, ASA 3 and 4 . The exclusion criteria were emergency surgeries, combined surgery, and patients who had already septal coronary artery alcoholization. All patients were monitored with pulse oximetry, 5-lead cardioscopy, invasive blood pressure, central venous pressure and transesophageal echocardiography (TEE). They were submitted to balanced general anesthesia with ethomidate 


\section{Journal of Cardiology \& Cardiovascular Therapy}

$(0.3 \mathrm{mg} / \mathrm{kg})$, fentanyl $(5 \mathrm{mcg} / \mathrm{kg})$, rocuronium $(0.6 \mathrm{mg} / \mathrm{kg})$ and sevoflurane $2 \%$. After intubation, the TEE probe was introduced and perioperative TEE exams were performed following the intraoperative TEE SCA/ASE guideline [4]. Parametric data are expressed as mean \pm standard deviation and categorical data in absolute numbers and percentages.

\section{Results}

A total of 4 patients were evaluated in the period from 2015 to 2017. Preoperative demographic data and preoperative echocardiographic data are shown in Table 1.

Table 1: Demographic and echocardiographic data in the preoperative period.

\begin{tabular}{|c|c|}
\hline Data & Values \\
\hline Patients, $\mathrm{n}$ & 4 \\
\hline Age, years & $61 \pm 8,7$ \\
\hline Weight, $\mathrm{Kg}$ & $63 \pm 8,3$ \\
\hline Height, $\mathrm{cm}$ & $158 \pm 5,0$ \\
\hline Feminine gender, $\mathrm{n}(\%)$ & $4(100)$ \\
\hline ASA 3 & $4(100)$ \\
\hline SAH, $\mathrm{n}(\%)$ & $4(100)$ \\
\hline Diabetes Mellitus, $\mathrm{n}(\%)$ & $0(0)$ \\
\hline Syncope during exercise, $\mathrm{n}(\%)$ & $1(25)$ \\
\hline Chest pain, $\mathrm{n}(\%)$ & $4(100)$ \\
\hline Pulmonary edema, $\mathrm{n}(\%)$ & $1(25)$ \\
\hline Ejection fraction (\%) & $66,5 \pm 1,3$ \\
\hline Left ventricle weight, $\mathrm{g}$ & $301,5 \pm 1.2$ \\
\hline End diastolic volume, $\mathrm{ml}$ & $101,8 \pm 10,1$ \\
\hline End systolic volume, $\mathrm{ml}$ & $29,7 \pm 8,9$ \\
\hline
\end{tabular}

ASA: American Society of Anesthesiologists physical status; SAH: Systemic Arterial Hypertension

Perioperative echocardiographic data are shown in Table 2.

Table 2: Perioperative echocardiographic data.

\begin{tabular}{|c|c|}
\hline Perioperative TEE Data & Values \\
\hline Peak gradient pre-CPB, mmHg & $114,4 \pm 50,6$ \\
\hline Peak gradient post-CPB, mmHg & $42,4 \pm 46,3$ \\
\hline Main gradient pre-CPB, mmHg & $52,4 \pm 19,9$ \\
\hline Main gradient post-CPB, mmHg & $21,4 \pm 25,6$ \\
\hline C-sept pre-CPB, cm & $1,4 \pm 0.4$ \\
\hline C-sept post-CPB, cm & $2,2 \pm 0,2$ \\
\hline CV pre-CPB, cm & $0,5 \pm 0.2$ \\
\hline CV post-CPB, cm & $0,4 \pm 0,3$ \\
\hline Ejection fraction pre-CPB, $\%$ & $66,5 \pm 1,3$ \\
\hline Ejection fraction post-CPB, $\%$ & $53,0 \pm 2,7$ \\
\hline
\end{tabular}

CPB: Cardio Pulmonary By-Pass; C-sep: distance between de mitral valve tip and the septal hipertrophy, CV: Contract Vein

The Figure 1 shows the LVOT obstructed by the anterior mitral leaflet (AMVL).

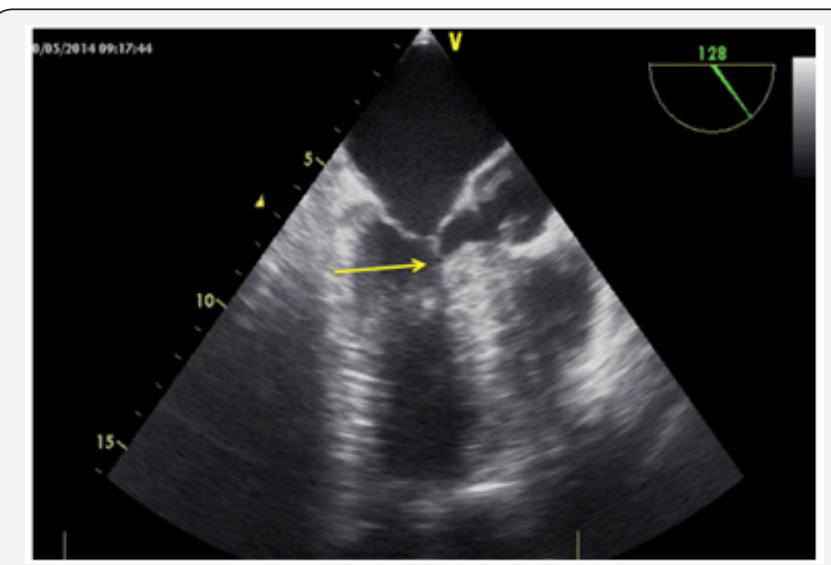

Figure 1: Midesophageal long-axis view demonstrating the anterior mitral leaflet obstructing the left ventricle outflow tract (yellow arrow).

The distance of mitral valve leaflets tip and the septal hypertrophy (C-sept) can be observed in the Figure 2.

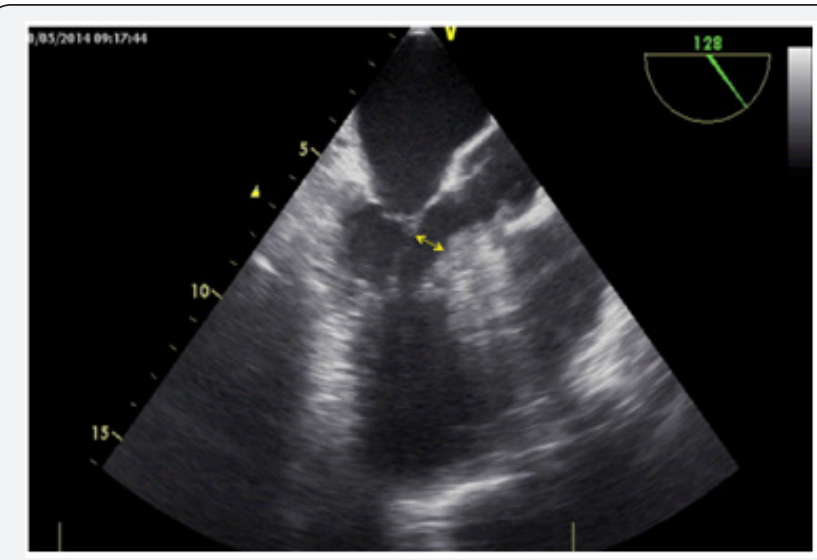

Figure 2: Midesophageal long-axis view showing the distance of mitral valve leaflets tip and the septal hypertrophy (C-sept) (yellow arrow).

In the Figure 3A \& 3B can be observed the SAM leading to an important mitral regurgitation and after the cardiopulmonary bypass (CPB), the mitral regurgitation is mild.

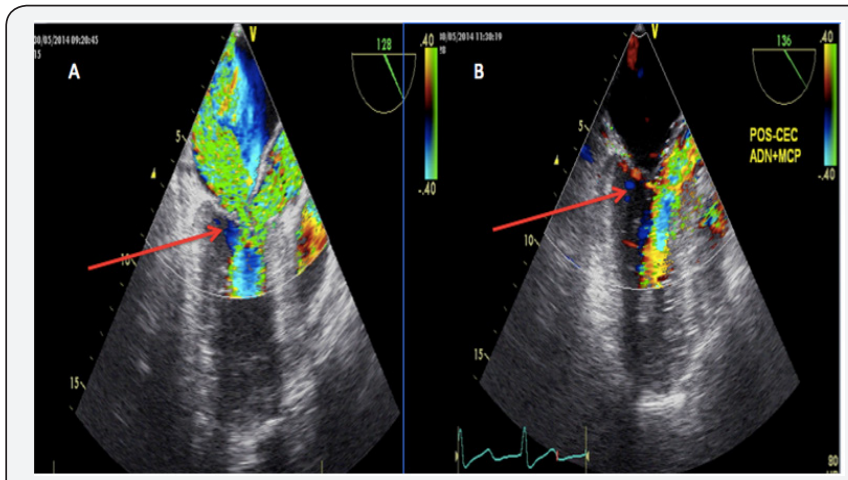

Figure 3A: Midesophageal long-axis view shows the sistolic anterior motion and the important mitral regurgitation (red arrow). Figure 3B: Midesophageal long-axis view shows the absence of SAM and the mild mitral regurgitation (red arrow).

Figure 4 shows the variation of the LVOT peak gradient between the pre-CPB period and the post-CPB period and the 
assessment of the distance between de mitral valve tip and the septal hypertrophy (C-sept) between the pre-CPB periods with the post- CEC.
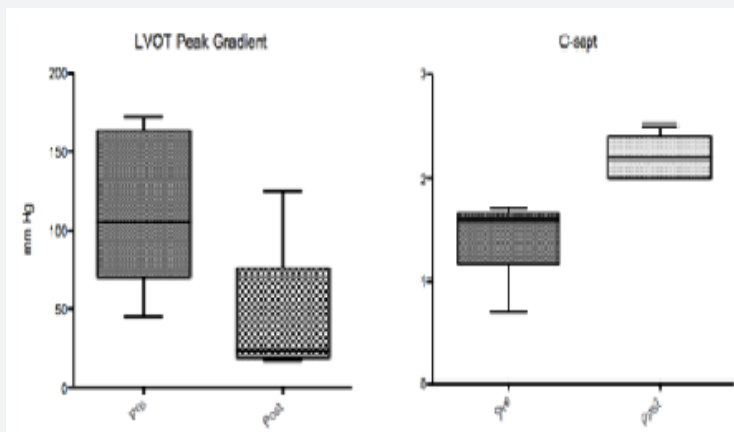

Figure 4: Evaluation of the LVOT peak gradient and C-septal distance between pre-CPB and post-BPB period. LVOT: Left Ventricle Outflow Tract; C-sept: distance between de mitral valve tip and the septal hipertrophy.

Table 3 shows the clinical outcome of the patients, the time of intubation in the ICU, length of ICU stay and hospital mortality.

Table 3: Patient's clinical outcomes.

\begin{tabular}{|c|c|}
\hline Clinical Outcomes & Values \\
\hline CPB clamp time, min & $50,3 \pm 30,7$ \\
\hline CPB time, min & $82 \pm 42,6$ \\
\hline Tracheal intubation time, hours & $32 \pm 27,0$ \\
\hline Time of length in ICU, days & $5 \pm 2,4$ \\
\hline Perioperative LOS, n (\%) & $1(25)$ \\
\hline Death in hospital, n (\%) & $1(25)$ \\
\hline
\end{tabular}

CPB: Cardiopulmonay By-Pass; ICU: Intensive Care Unit; LOS: Low Output Syndrome

\section{Discussion}

In these 4 cases of septal myectomy procedure, the perioperative TEE assisted the decision making regarding the anatomical structures to be resected. TEE also showed possible complications of the procedure like ventricular septal perfuration, aortic regurgitation, mitral regurgitation and persistent LVOT obstruction [1-3]. We concluded in our study, that myectomy procedure increases the $\mathrm{C}$-sept distance and decreases the SAM, leading a lower LVOT peak gradient and lower mitral regurgitation [1-3].

\section{References}

1. Hensley N, Dietrich J, Nyhan D, Mitter N, Yee MS, et al. (2015) Hypertrophic cardiomyopathy: A review. Anest analg 120(3): 554-569.

2. Hymel BJ, Townsley MM (2014) Echocardiographic assessment of systolic anterior motion of the mitral valve. Anest analg 118(6): 11971101.

3. Coyne JT, Alfirevic A (2013) Reorientation of an obstructive, hypermobile papillary muscle: Intraoperative echocardiographic assessment. Anest Analg 116(5): 989-992.

4. Hahn RT, Abraham T, Adams MS, Bruce CJ, Glas KE, et al. (2013) Guidelines for performing a comprehensive transesophageal echocardiographic examination: Recommendations from the american society of echocardiography and the society of cardiovascular anesthesiologists. J Am Soc Echocardiogr 26(9): 921-964.

\begin{tabular}{|l|}
\hline \multicolumn{1}{|c|}{ Your next submission with Juniper Publishers } \\
will reach you the below assets \\
- Quality Editorial service \\
- Swift Peer Review \\
- Reprints availability \\
- E-prints Service \\
- Manuscript Podcast for convenient understanding \\
- Global attainment for your research \\
- Manuscript accessibility in different formats \\
( Pdf, E-pub, Full Text, Audio) \\
- Unceasing customer service \\
Track the below URL for one-step submission \\
https://juniperpublishers.com/online-submission.php \\
\hline
\end{tabular}

